\title{
Discussion Board: A Learning Object
}

\author{
Keith Harman \\ Northcentral University \\ Prescott, AZ USA
}

kharman@ncu.edu

\author{
Alex Koohang \\ University of Wisconsin - \\ Milwaukee, Milwaukee, USA
}

koohang@uwm.edu

\section{Abstract}

This paper argues that a discussion board as an integral part of e-learning is a learning object worthy of scrutiny. It explores how current praxis and theory on learning objects can be used to improve the development and application of discussion boards. Implications for discussion board as learning objects are discussed. They include: (1) accessing learning objects via discussion boards, (2) using and sharing learning objects via discussion boards, (3) creating a cycle of composition and decomposition of learning objects via discussion boards, and (4) using computer agents to improve access and communication of the data archived in discussion boards. Recommendations for future research are made.

Keywords: Learning object, discussion board, contextualization, constructivism, standards

\section{Introduction}

The primary purpose of this paper is to explore how current praxis and theory on learning objects can be used to enhance the development and application of discussion boards. This paper is organized in manner consistent with its purpose.

The paper's introductory remarks confirm two key points or working assumptions that underlie the purpose of the paper. Firstly, it is shown that discussion boards represent the primordial milieu in which e-learning and communities of learning emerged and that discussion boards remain an integral tool for e-learning. Secondly, it is shown that conceptualizing discussion boards as learning objects would represent a paradigm shift with many potential benefits for theory and praxis in e-learning.

The discussion then shifts to a focus upon common ways in which discussion boards are used as learning objects. Next is a discussion that presents creative ways to use discussion boards as learning objects. Conclusions and recommendations for future research on the use of discussion boards as learning objects round out the paper.

Material published as part of this journal, either on-line or in print, is copyrighted by the publisher of the Informing Science Journal. Permission to make digital or paper copy of part or all of these works for personal or classroom use is granted without fee provided that the copies are not made or distributed for profit or commercial advantage AND that copies 1) bear this notice in full and 2) give the full citation on the first page. It is permissible to abstract these works so long as credit is given. To copy in all other cases or to republish or to post on a server or to redistribute to lists requires specific permission and payment of a fee. Contact Publisher@ijklo.org to request redistribution permission.

\section{Learning Objects}

Hodgins (2000, p. 1) states that learning objects "represent a completely new conceptual model for the mass of content used in the context of learning. They are destined to forever change the shape and form of learning, and in so doing, it is anticipated that they will also usher in as unprecedented efficiency of learning 
content deigns, development, and delivery.” Hodgins’s viewpoints are shared by Wiley (2002) and Gaible, Hannafin, Merrill, Spector, Visser, and Wiley (2002).

Learning objects are becoming increasingly accepted in the learning community, however; the discussion about a common definition for learning objects remains. Thus far there is no generally accepted definition within the learning object community. The literature contains many definitions of learning objects. These vary from anything digital or non-digital with pedagogical value that supports learning (Downes, 2003a; Friesen, 2001, IEEE, 2002, Quinn \& Hobbs, 2000) to anything digital with pedagogical value that supports learning (Sosteric \& Hesemeier, 2003; Wiley, 1999). In addition, the definitions vary in the use of terminology that describes learning objects. For instance, learning objects have referred to as content object (OASIS, 2003); educational object (Friesen, 2001); information object (Wiley, 1999); knowledge object (Merrill, 1999); learning resource (IMS Global Learning Consortium, 2000); media object (ADL, 2001); and reusable learning object (Cisco Systems, 2001).

Wiley (2000) provides an extensive set of criteria regarding learning objects, especially that they are greatly impacted by their sheer size although it is their reusability that makes them so potentially valuable. The reusability of learning objects and their ultimate efficacy is linked to the issue of contextualization, i.e. the extent to which a given learning object may be used in one situation or setting versus another (Wiley, Padron, Lambert, Dawson, Nelson, Barclay, \& Wade, 2003). Given this assumption there is a temptation to further assume some type of economy of scale for learning objects (i.e. assuming a positive relationship between the size of a learning object, its context, and its subsequent reusability vis-à-vis some universe or set of contexts). The literature, however; suggests that too broad a context may decrease the efficacy of a learning object unless the learner is provided highly extensive guidance or direction as regards context and application (Hill \& Hannafin, 2001; Wiley, 2000; Wiley et al., 2003).

Consider the following scenario: A learning object consists of the content and metadata. Once the content is created (the chunk), it is tagged with metadata. It is then stored in a place known as learning object repository. An instructor can use a Learning Content Management System (LCMS) to pull together specific and relevant learning objects from the repository to create a course.

This paper goes beyond this scenario and takes into consideration that learning objects may be categorized in a variety of ways including those that are highly complex and thus are likely to be used extensively on an intra-contextual and an inter-contextual basis (Wiley, 2000) and that a learning object is anything digital or non-digital with pedagogical value that supports learning (Downes, 2003a; Friesen, 2001, IEEE, 2002, Quinn \& Hobbs, 2000).

In light of these considerations, this paper asserts that a learning object is not merely a chunk of information packaged to be used in instructional settings. A learning object, therefore, can include anything that has pedagogical value - digital or no-digital such as a case study, a film, a simulation, an audio, a video, an animation, a graphic image, a map, a book, or a discussion board so long as the object can be contextualized by individual learners. The learner must be able to make meaningful connections between the learning object and his/her experiences or knowledge he/she previously mastered.

\section{Discussion Board as a Learning Object}

Based on the above assertion, this paper includes a discussion board as a learning object that is worthy of scrutiny. Whatis.com (2002) states that a discussion board is a general term for an online bulletin board. It is also known by different terms such as "discussion group", "discussion forum", "message board”, and "online forum". This paper uses the term discussion board to include all of these terms. 
If anything, the discussion board is of historical value because it was the setting or the context for the original digital learning communities (Slaton, 2001). Nevertheless, historical analysis is not the most important benefit to be gained from studying discussion boards. They are a powerful, yet obsequious learning object whose value as a tool for e-learning has yet to be fully realized either in a completely online or in a hybrid (a combination of online and face-to-face) instructional setting (Barker, 2001; Hill, Seungyeon, \& Raven, 2001; King, 2001).

The precursor of the discussion board was the USENET, a series of virtual bulletin boards that as early as the mid-1970s allowed anyone with access to the Internet (or its precursors) to post a message to any "newsgroup" at any time (Stewart, 2004). The USENET has been compared to an "electronic news magazine" and a "world town meeting” (Hauben, 1996).

A discussion board is referred to as "reader centered" or focusing upon the user of information as opposed to the creator of information (Hauben, 1996). This assumption that the discussion board (and its precursors) focuses upon the user of information parallels the idea that learning objects are useful only when put into context (i.e. the process of contextualization). As a result, this paper asserts that the discussion board and its precursors constituted the first significant learning objects in cyberspace.

The discussion board remains an integral part of e-learning (Barker, 2001; Clyde, 2004; King, 2001). Each of the major platforms for e-learning incorporates a discussion board. The discussion board however is rarely, if ever, thought of as a learning object, per se. Instead a discussion board is usually conceived of as a place (albeit virtual) in which learning objects are delivered, stored, and used (Barta-Smith \& Hathaway, 2000).

It is the perception of the discussion board as a place that presents the proverbial "blessing and a curse." The perception of the discussion board as merely a place is an exceptionally limited perspective, especially given current definitions of learning objects, (e.g. Wiley, 2000). Yet the prevailing perception of the discussion board as a place gives it a sense of context - a seminal or fundamental characteristic of any learning object. Consequently, either the discussion board constitutes some type of "special case" of learning object or it possesses all of the characteristics that are common to all learning objects. In either case a deeper understanding of the discussion board and its potential uses merits serious consideration.

Parrish (2004) suggests that current debates on how to define the term learning object may be reconciled if a learning object is viewed as a process or strategy as opposed to an artifact, i.e. the Object Oriented Instructional Design (OOID) approach. Given that a discussion board is a place people visit (albeit virtually) to accomplish something, the discussion board fits a process-based definition just as readily as it fits an artifact-based definition. The discussion board, regardless of the definition one applies (artifact-based versus process-based) may be defined as a learning object.

Given its historical significance the discussion board may help us understand the future of elearning because it tells us about the history of e-learning. Researchers such as Cox (2000) and Miller and Slater (2000) would consider the archives of early discussion board content to be a treasure trove for research on the uses of discussion boards and for research on those who used them.

On a more practical level, Rosson and Carroll (1996) demonstrated that the discussion board offers a highly useful context to simulate scenarios or conditions that may be used to train programmers in the fundamentals of object-oriented design. Chen and Hung (2002, p. 279) argue that the effectiveness of online discussion boards can be improved through technological support for "personalized knowledge representation" and the use of "idea artifacts to facilitate internaliza- 
tion of learners' collective knowledge into personalized knowledge.” The discussion board, therefore, deserves greater attention as a learning object that may enhance e-learning.

\section{Discussion Board Applications}

In many ways the discussion board is used as it was during the infancy of the Internet. Today, the discussion board is primarily used as a forum to conveniently communicate with members of a group or an online community and to seek assistance and support from that group or online community (Hauben, 1996; King, 2001; Nicholson \& Bond, 2003; Slaton, 2001). Because the discussion board features asynchronous interaction, it is archival in nature.

However, the discussion board of today is a far richer and engaging environment than the discussion board of yesterday. Improved search engines and help functions are common features. Users are usually able to upload files in at least a number of common file formats rather than being constrained to text messages. Editing capabilities are vastly improved, often including "spell check." Variations in font and color of text are usually possible.

Features such as hyperlinks and search engines mean that the discussion board of today is as much a portal as it is a destination. This is a subtle but important shift since the expertise and support provided users can now conveniently incorporate an inter-community dimension (indeed a global dimension) instead of being limited to the expertise and support available from the users of a given, i.e. or single discussion board. Because the discussion board combines an archival and search function, the discussion board becomes a place to create tags for metadata (although it is more likely to be a place to search for tags for metadata).

It is important to distinguish discussion boards from "weblogs.” Weblogs (more popularly referred to as "blogs" are beyond the scope of this paper. Blogs share many similarities with discussion boards (Wikipedia, 2005) but the primary focus of a weblog is upon accessing and distributing content whereas the primary focus of a discussion board is upon discussion or dialog regarding content.

The discussion board thus may be used as a "context board." For example, the concept of using the discussion board as a "context board" fits well within Downes' (2003b) recommendation for using syndicated learning content:

"It is important to understand the advantage offered by dynamic syndicated content. The idea is that content is maintained and updated in one place, which relieves any users of that type of content from the burden of making sure the content is up to date. If, for example, a learning object on (say) linear functions is offered by a university and used by dozens of schools around the country, and if the learning object is updated or replaced, then a small change in the XML file distributed to these schools can implement the change; in this way, the schools themselves need not worry about updating links or being sure they are using the most recent version.” (paragraph 10)

If the discussion board is used as that "place" described by Downes, the discussion board becomes a portal and a network node or hub in a distributed learning syndicate or network. It is at this point that the discussion board becomes a mass medium and the discussion board more readily fits within the constructivist rubric or philosophy that underlies e-learning.

\section{Theoretical Implications}

Downes (2003a) states “... an object is a learning object if it is used in learning. No other criteria apply. What makes it a learning object is that it has been used in learning, that there is some educational context in which the object was found to have pedagogical value.” Koohang (2004) asserts that learning object's ultimate purpose is to optimize, enhance, and facilitate learning. 
As mentioned earlier, when a discussion board is used as a learning object it must offer some pedagogical meaning. The learner must be able to contextualize the new knowledge by making connections between that knowledge and his/her experiences or previously mastered knowledge. An appropriate model of instructional design that includes appropriate learning theories and principles within a discussion board may allow the learner to contextualize the new knowledge.

Constructivism is a learning theory that defines learning as a change in meaning constructed from prior experience (Newby, Stepich, Lehman, \& Russell, 1996). Constructivism is an active process of constructing knowledge in such a way that the learner builds on prior knowledge and experience to draw meaning and construct new knowledge (Walker \& Lambert, 1995). Woolfolk (1993, p. 485) explains the constructivist view of the learning process as:

... The key idea is that students actively construct their own knowledge: the mind of the student mediates input from the outside world to determine what the student will learn. Learning is active mental work, not passive reception of teaching.

Constructivism intends for the learners to make individualized and often unique connections in constructing their knowledge by bringing various knowledge, experience, and interests to the learning event. In this learning situation, students are encouraged to actively communicate with each other. They are encouraged to react, in a collaborative manner, to each other's perspectives. This makes students responsible for knowledge generation and learning becomes active (Maxwell, 1995).

A discussion board as a learning object is a prime candidate for adopting the constructivism learning theory. Constructivism learning theory includes elements such collaboration, cooperation, exploration, higher-order thinking skills, knowledge construction, learner driven goals and objectives, multiple perspectives, multiple representations of content/idea/concept, negotiation among learners, learners previous experience, real-world situations/problems, social disclosure, social negotiation, and the use of primary sources of data. Research has favored applying constructivism learning theory to the design of instruction in learning objects and e-learning settings (Bannan-Ritland, Dabbagh, \& Murphy, 2000; Hung, 2001; Hung \& Nichani, 2001; Oliver, 1999).

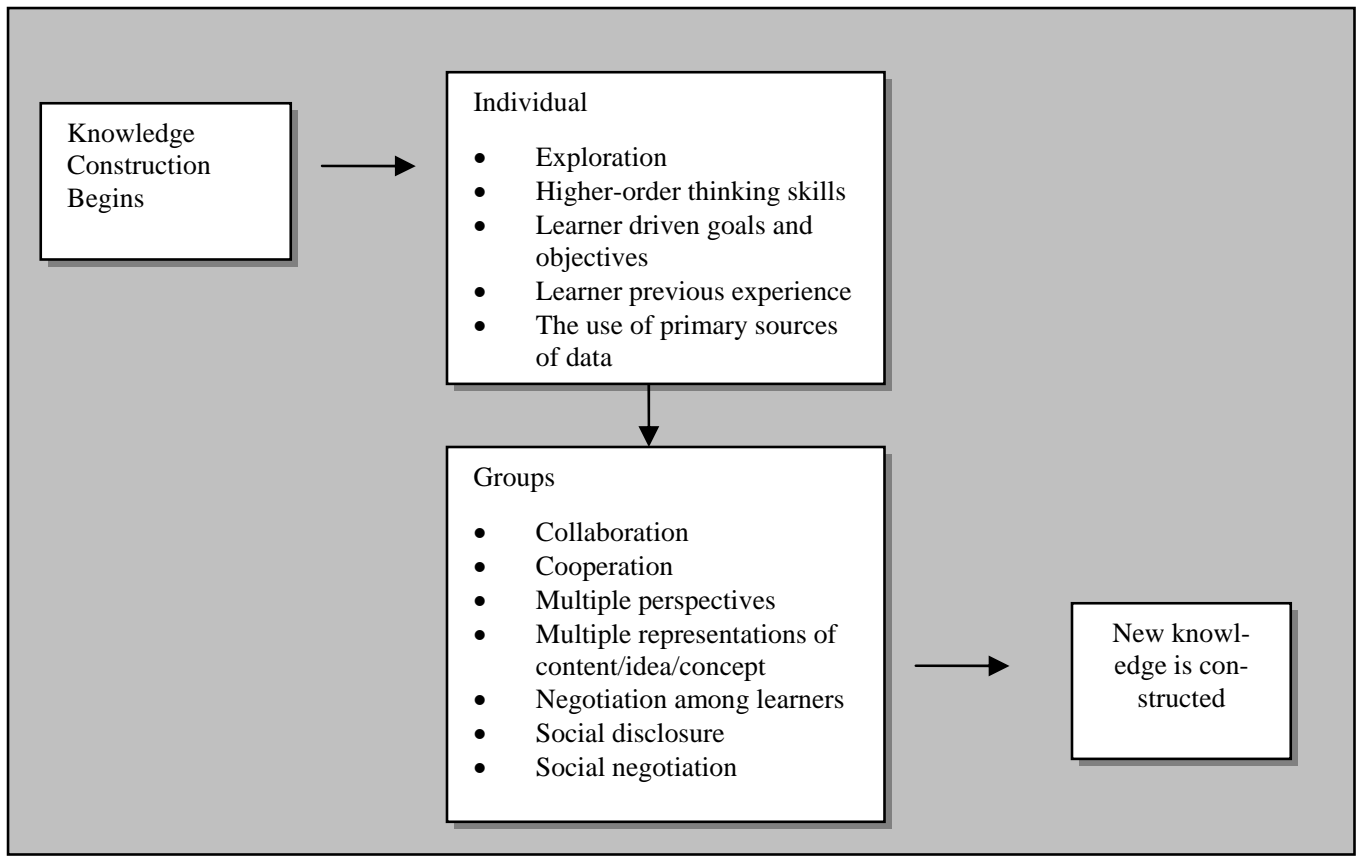

Figure 1: Knowledge creation process in discussion board - applying constructivism 
Figure 1 shows the process of knowledge construction in a discussion board where constructivism principles are applied and learning is contextualized.

The knowledge construction begins by presentation of a real-world problem or situation. Learners are then encouraged to react to the problem or situation. The activity begins by emphasizing elements such as exploration, higher-level thinking skills, and use of primary sources of data. Learners are encouraged to independently derive goals and objectives to solve the problem. Learners are also encouraged to use their own previous experience(s) and apply them to the problem/situation.

Next in a collaborative and cooperative setting, learners create a thread of discussion engaging themselves in dialogue with each other. Multiple representations of content, ideas, and concepts, are at hand. This creates social discourse that allows learners to reinforce their ideas and in some cases even change their own original thoughts - social negotiation. They will build a combined knowledge with multiple perspectives that construct meaning and new knowledge.

The facilitator will also engage in dialog along with the learners. The facilitator provides feedback, encouragement, and other types of support to motivate learners.

\section{Implications of Discussion Board as a Learning Object}

By standardization, learning objects can be interoperable. Interoperability is the ability of the object to be transported in any platform, i.e., the object is not platform dependent and can function in any delivery media regardless of technology and protocol.

Hodgins and Conner (2000, paragraph 7) referred to LEGO ${ }^{\mathrm{TM}}$ as a good example of standards. He explained that "All LEGO blocks adhere to one absolute standard for pin size. Every LEGO piece, no matter what shape, color, size, age, or purpose can always be snapped together with any others piece because of their uniformly shaped pins. This allows children of all ages to create, deconstruct, and reconstruct LEGO structures easily and into most any form they can imagine.” Listed below are a few learning standards.

- IEEE LO Metadata (LOM) Learning Technology Standards Committee (LTSC) P1484 (http://ltsc.ieee.org/)

- Advanced Distributed Learning (ADL) Initiative - Shareable Courseware Object Reference Model (SCORM) (http://www.adlnet.org/)

- $\quad$ IMS (Instructional Management System) Global Learning Consortium (http://www.imsproject.org/)

Standards can ensure interoperability that is critical to a discussion board as a learning object in a distributed e-learning system. The designers of discussion boards should always consider learning object standards. They must team up with the standardization community to create discussion boards that are based on open standards.

While tremendous efforts are being made to build learning object standards, the Institute of Electrical and Electronics Engineers Learning Object Metadata IEEE LOM (2002) seems to have picked up the speed in the learning object community and it is expected that other standards to follow IEEE LOM. The IEEE LOM consists of nine categories that are encoded in XML. They are general, lifecycle, meta-metadata, technical, educational, rights, relation, annotation, and classification. Consider the several selected objectives proposed by IEEE LOM:

- To enable learners or instructors to search, evaluate, acquire, and utilize learning objects. 
- To enable the sharing and exchange of learning objects across any technology supported learning systems.

- To enable the development of learning objects in units that can be combined and decomposed in meaningful ways.

- To enable computer agents to automatically and dynamically compose personalized lessons for an individual learner.

These objectives have practical implications for discussion boards as learning objects. The implications include accessing learning object; using and sharing learning object; composition and decomposition of learning objects; and using computer agents.

\section{Accessing Learning Objects Via Discussion Boards}

The discussion board is the ideal pace to literally put a learning community and its learning objects on the same page. This is more than a mere play on words. For a learning community to emerge and to function effectively, its member must achieve some minimal level of shared or congruent contextualization. A discussion board can be used to start this process.

\section{Using and Sharing Learning Objects Via Discussion Boards}

Contextualization will be subsequently augmented when the discussion board is used to set the parameters for learning community members' use of and communication about learning objects. Substantive dialog and sharing will itself generate new learning objects as new understandings and knowledge are created.

\section{Composition and Decomposition of Learning Objects Via Discussion Boards}

The process of composition and decomposition will create a cycle of learning that can continue indefinitely. An instructor or facilitator will be able to ensure that this is a conscious process by using queries or cues that motivate learners to engage in synthesis and analysis of learning objects. An instructor or facilitator will also have an opportunity to use queries or cues that fit within a given taxonomy.

\section{Using Computer Agents}

Using the discussion board as a "search universe" offers a way to limit search results to those that fit the precise context and thus provide a maximum benefit. Additionally, the guidance or parameters drawn up for computer agents provides an opportunity for a learning community, facilitators, and information science professionals to create an even larger community of learners. Creating this larger community of learners may require facing and dealing with the issues of intellectual property and privacy. The use of computer agents presupposes an archival function. The archival function provides a means by which a discussion board becomes a document or relic as opposed to an artifact, indeed the discussion board can become a living artifact in the purest sense of the term. 


\section{Conclusions}

The discussion board is a learning object that contains chunks of information or sub-objects that are themselves made up of smaller components or sub-objects. Additionally, a discussion board as a learning object is a sub-object or chunk of a larger learning object. It is simply a matter of contextualization.

This is an important insight because it confirms what has been learned in the literature about learning objects. It also confirms that learning objects generally conform to certain observable phenomena in nature, namely, interval numbers. Being infinitely divisible, the discussion board demonstrates that learning objects resemble interval-level data that are by definition equally and infinitely divisible. Being infinitely compoundable, the discussion board also demonstrates that learning objects resemble interval-level data because as is the case for interval-level data the process of division can be reversed and the process of multiplication can move towards a larger data value or larger datum.

If learning objects resemble interval data then do bits resemble ordinal-level or categorical-level data? Or is this simply an issue of contextualization? Will researchers and information scientists continue to identify smaller and smaller contexts in a manner similar to the journey taken by theoretical physicists? Will researchers and information scientists come to a point, like theoretical physicists, that there is an understanding of the practical and philosophical problems posed by an ever-expanding universe of learning objects? In what ways will technological advances enable us, like theoretical physicists, to answer previously difficult or complex questions (e.g., the Hubble Telescope enabling astronomers to see into deep space)?

These are issues that merit future research because they may help researchers and information scientists come to grips with fundamental definitional problems and to expand the taxonomy of learning objects - an enhanced taxonomy of contexts and a richer understanding of how and why contextualization works. For example, is it possible that contextualization is essentially algorithmic in nature, i.e. is it an iterative process? If so, what does that imply for developing and using learning objects?

\section{References}

ADL. (2001). Sharable content object reference model Version 1.2: The SCORM overview. Retrieved December 15, 2004 from http://www.adlnet.org/ADLDOCS/Documents/SCORM_1.2_Overview.pdf

Bannan-Ritland, B., Dabbagh, N. \& Murphy, K. (2000). Learning object systems as constructivist learning environments: Related assumptions, theories, and applications. In D. A. Wiley (Ed.), The Instructional Use of Learning Objects: Online Version. Retrieved December 15, 2004 from http://reusability.org/read/chapters/bannan-ritland.doc

Barker, P. (2001). Creating and supporting online communities. ERIC, ED466133.

Barta-Smith, N. A. \& Hathaway, J. T. (2000). Making cyberspaces into cyberplaces. Journal of Geography, 99 (6), 253-265.

Chen, D. \& Hung, D. (2002). Personalised [sic] knowledge representations: The missing half of online discussion forums. British Journal of Educational Technology, 33 (3), 279-290.

Cisco Systems. (2001). Reusable learning object strategy. Designing information and learning objects through concept, fact, procedure, process, and principle templates. Retrieved December 20, 2004 from http://www.cisco.com/warp/public/10/wwtraining/elearning/implement/rlo_strategy.pdf

Clyde, L. A. (2004). Digital learning objects. Teacher Librarian, 31 (4), 55-57.

Cox, R. J. (2000). Closing an era: Historical perspectives on modern archives and records management. Westport, Connecticut: Greenwood Press. 
Downes, S. (2003a). Designing learning objects. Retrieved December 21, 2004 from http://www.ibritt.com/resources/dc_objects.htm

Downes, S. (2003b). Using syndicated learning content. Retrieved January 6, 2005 from http://learnscope.flexiblelearning.net.au/LearnScope/golearn.asp?Category $=11 \&$ DocumentId $=4845$

Friesen, N. (2001). What are educational objects? Interactive Learning Environments, 9 (3), 219-230.

Gaible, E., Hannafin, M., Merrill, D., Spector, M., Visser, J., \& Wiley, D. (2002). Learning objects technology: Implications for educational research and practice. Panel presentation proposal for the 2002 Annual Meeting of the American Educational Research Association. Retrieved December 17, 2004 from http://www.learndev.org/LearningObjectsAERA2002.html

Hauben, R. (1996). Chapter 2. The evolution of USENET: The poor man's ARPANET. In Netizens, On the history and impact of the Internet. Retrieved December 29, 2004 from http://www.columbia.edu/ rh120/ch106.x02

Hill, J., \& Hannafin, M. J. (2001). Teaching and learning in digital environments: The resurgence of resource-based learning. Educational Technology Research and Development, 49 (3), 37-52.

Hill, J. R., Seungyeon, H., \& Raven, A. (2001). Build it and they will stay: A research-based model for creating community in web-based learning environments. ERIC, ED470090.

Hodgins, H. W. (2000). The future of learning objects. In D. A. Wiley (Ed.), The Instructional Use of Learning Object. Retrieved December 29, 2004 from http://reusability.org/read/chapters/hodgins.doc

Hodgins, W. \& Conner, M (2000). Everything you wanted to know about learning objects but were afraid to ask. Retrieved December 29, 2004 from http://www.linezine.com/2.1/features/wheyewtkls.htm

Hung, D. (2001). Design principles for web-based learning; implications for Vygotskian thought. Educational Technology, 41 (3), 33-41.

Hung. D. \& Nichani, M. (2001). Constructivism and e-learning: balancing between the individual and social levels of cognition. Educational Technology, 41 (2), 40-44.

IEEE. (2002). IEEE Standard for Learning Object Metadata. 1484.12.1-2002.

IMS Global Learning Consortium. (2000). IMS learning resource meta-data best practices and implementation guide. Retrieved December 29, 2004 from http://www.imsglobal.org/metadata/imsmdv1p2p1/imsmd_bestv1p2p1.html

King, K. (2001). Educators revitalize the classroom "bulletin board": A case study of the influence of online dialog on face-to-face classes from an adult learning perspectives. Journal of Research on Computing in Education, 33 (4), 337-354.

Koohang, A. (2004). Creating learning objects in collaborative e-learning settings. Issues in Information Systems, 4 (2), 584-590.

Maxwell, L. (1995). Integrating open learning and distance education. Educational Technology, 35 (6), 4348.

Merrill, M. (1999). Instructional Transaction Theory (ITT): Instructional design based on knowledge objects. In C. M. Reigeluth (Ed.), Instructional-design theories and models: A new paradigm of instructional theory (pp. 397- 424). Mahwah, NJ: Lawrence Erlbaum Associates.

Miller, D. \& Slater, D. (2000). The Internet: An ethnographic approach. Oxford: Berg.

Newby, T. J., Stepich, D. A., Lehman, J. D. \& Russell, J. D. (1996). Instructional technology for teaching and learning: Designing instruction, integrating computers, and using media. NJ: Prentice Hall.

Nicholson, S.A. \& Bond, N. (2003). Collaborative reflection and professional community building: An analysis of preservice teachers' use of an electronic discussion board. Journal of Technology and Teacher Education, 11 (2), 259-279. 
OASIS. (2003). Sharable content object reference model initiative (SCORM). Retrieved December 29, 2004 from http://xml.coverpages.org/scorm.html

Oliver, R. (1999). Exploring strategies for online teaching and learning. Distance Education, 20 (2), 240254.

Parrish, P. (2004). The trouble with learning objects. Educational Technology Research and Development, 52 (1), 49-67.

Quinn, C. \& Hobbs, S. (2000). Learning objects and instructional components. Educational Technology and Society, 3 (2). Retrieved January 02, 2005 from http://ifets.ieee.org/periodical/vol_2_2000/discuss_summary_0200.html

Rosson, M. B. \& Carroll, J. M. (1996). Scaffolded examples for learning object-oriented design. Communications of the ACM, 39 (4), 46-47.

Slaton, J. (2001). Remembering community memory The Berkeley beginnings of online community. Retrieved December 21, 2004, from http://www.sfgate.com/cgiin/article.cgi?file=/gate/archive/2001/12/13/commmem.DTL

Sosteric, M., \& Hesemeier, S. (2002). When is a learning object not an object: A first step towards a theory of learning objects. International Review of Research in Open and Distance Learning, 3 (2). Retrieved December 29, 2005 from http://www.irrodl.org/content/v3.2/index.html

Stewart, W. (2004). Usenet. In Living Internet. Retrieved December 29, 2004 from http:/livinginternet.com/u/u.htm

Walker, D., \& Lambert, L. (1995). Learning and leading theory: A century in the making. In L. Lambert, D. Walker, D. P. Zimmerman, J. E. Cooper, M. D. Lambert, M. E. Gardner, \& P. J. Ford Slack, The constructivist leader (pp. 1-27). NY: Teachers College Press, Columbia University.

Whatis.com. (2002). Definitions: Discussion board. Retrieved January 04, 2005 from: http://searchvb.techtarget.com/sDefinition/0,sid8_gci211961,00.html

Wikipedia. (2005). Weblog. In Wikipedia the Free Encyclopedia. Retrieved February 16, 2005 from: http://en.wikipedia.org/wiki/Weblog

Wiley, D. (1999). The Post-LEGO Learning Object. Retrieved December 15, 2004 from http://wiley.ed.usu.edu/docs/post-lego/

Wiley, D. (2000). Connecting learning objects to instructional design theory: A definition, a metaphor, and a taxonomy, in The instructional use of learning objects. Retrieved December 15, 2004 from http://reusability.org/read/chapters/wiley.doc

Wiley, D., Padron, S., Lambert, B., Dawson, D., Nelson, L., Barclay, M. \& Wade, D. (2003). Using O2 to Overcome Learning Objects Limitations. Retrieved December 28, 2004 from http://www.cs.kuleuven.ac.be/ erikd/PRES/2003/LO2003/Wiley.pdf

Woolfolk, A. E. (1993). Educational psychology, Boston: Allyn and Bacon. 


\section{Biographies}

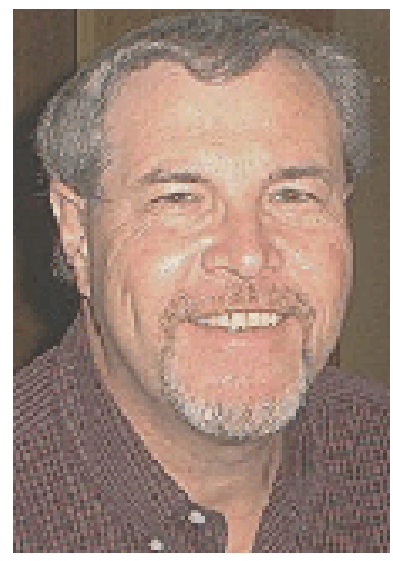

Keith Harman, Ph.D. is Chair of the Department of Business \& Technology at Northcentral University. His 25 years of experience in academe include stints as a faculty member, department chairperson, dean, and academic research administrator. In addition to three books on information management and strategic planning and over two dozen publications and presentations in journals and proceedings, he has served as a guest lecturer and consultant for Fortune 1000 corporations, major universities, private foundations and government agencies.

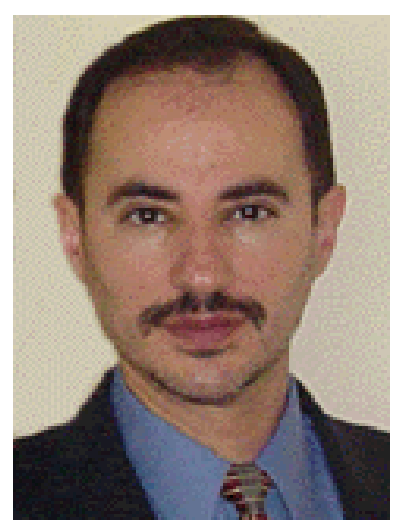

Alex Koohang, Ph.D. is Director of Undergraduate Programs, School of Information Studies, University of Wisconsin at Milwaukee. His 20 years of experience in higher education include stints as a faculty member, program director, curriculum product manager, visiting professor, and division director. He has authored or co-authored many papers. Dr. Koohang's current research interest includes e-learning, learning objects, and usability. 